\title{
Documenting and Explaining the Common AAB Pattern in Music and Humor: Establishing and Breaking Expectations
}

\author{
Paul Rozin \\ University of Pennsylvania
}

\author{
Alexander Rozin \\ West Chester University
}

\author{
Brian Appel and Charles Wachtel \\ University of Pennsylvania
}

\begin{abstract}
The AAB pattern consists of two similar events followed by a third dissimilar event. The prevalence of this pattern in the aesthetic domain may be explained as violation of expectation: A minimum of two iterations is required to establish a repetitive pattern; once established, it is most efficient to promptly violate the expected continuance of the pattern to produce the maximal aesthetic effect. We demonstrate the prevalence of this pattern (in comparison to $\mathrm{AB}$ or $\mathrm{AAAB}$ ) in a representative sample of a variety of musical genres and in a representative sample of repetitive genre of jokes. We also provide experimental evidence that the $\mathrm{AAB}$ pattern in jokes is maximally effective in producing a humor response in participants.
\end{abstract}

Keywords: music, humor, jokes, pattern, $\mathrm{AAB}$

The aesthetic response clearly falls in the domain of affect. Whether it can properly be called an emotion depends on matters of definition. In some respects, it can be thought of as like a simple pleasure, highlighting similarities between, for example, the response to chocolate and the response to Mozart (Rozin, 1999). On the other hand, the appraisals that lead to an aesthetic response seem much more complex than those to simple tastes or those to many standard emotion elicitors. Although the aesthetic response has not been subjected to the same amount of empirical investigation as have most of the "basic" emotions, there have been some fundamental studies and observations, summarized and well organized in the earlier phases by Daniel Berlyne (1971). In line with the appraisal view of emotion (e.g., Ellsworth \& Scherer, 2003; Frijda, 1986; Scherer, 1984), the focus has been on the interpretation of stimulus structure. Serious attempts to study and understand the aesthetic experience, in literature, the visual arts, and music have been made (e.g., Berlyne, 1971; Oatley, 2003). One theme that has emerged from much of the work has been the importance of novelty in the aesthetic experience. Novelty figures as a primary factor in most emotion appraisal theories (e.g., Ellsworth \& Scherer, 2003; Frijda, 1986; Scherer, 1984). Berlyne (1971) emphasized the role of novelty, linked to his emphasis on arousal and subsequent arousal reduction as central to the aesthetic experience. More recently, Kubovy (1999) has emphasized the

Paul Rozin, Department of Psychology, University of Pennsylvania, Philadelphia, Pennsylvania; Alexander Rozin, Department of Music Theory and Composition, West Chester University, West Chester, Pennsylvania; Brian Appel and Charles Wachtel, University of Pennsylvania, Philadelphia, Pennsylvania.

Correspondence concerning this article should be addressed to Paul Rozin, Department of Psychology, University of Pennsylvania, 3720 Walnut Street, Philadelphia, PA 19104-6241. E-mail: rozin@psych.upenn.edu sequence of emotions or affect in the aesthetic experience. Critical to Berlyne's analysis is the idea that moderate arousal and its resolution may be central to aesthetic enjoyment. One way of describing this is that something new but seemingly comprehensible, and hence challenging, forms the basis for an aesthetic response.

This general description can be made more specific in terms of the idea of violation of expectation within certain constraints. The issue is raised most explicitly in music theory. Leonard Meyer's $(1956,1973,1973)$ account of the appreciation of music is built around the idea that familiar musical styles set up expectations, and that it is the realization of these expectations, or modest violations of them, that constitutes the core of the aesthetic experience. Meyer has elaborated this principle along many dimensions in a generally successful attempt to explain the appeal of new pieces within a familiar style. In his view, the development of expectations arises primarily from the internalization of the syntax of the musical style (see Gaver \& Mandler, 1987, for a similar treatment).

One problem with this view is that it does not easily account for the repeated enjoyment of the same piece of music after it has become so familiar that the listener knows exactly what to expect. Eugene Narmour (1990, 1991, 1992) has modified and extended Meyer's implication-realization view in a way that accounts for the enjoyment of repetitions. He postulates, with some evidence, that there are a set of innate auditory expectations, along with the acquired syntax of style. These rather primitive innate expectations probably have their origin in the real world. One of them is that if something repeats, we innately expect it to continue to repeat. Under this assumption, the violation of a repetition, though it may be anticipated or expected, is still a violation of an innate expectation. An alternative to Narmour's account that leads to the same outcome is that what he designates as innate expectations are acquired, based on many repeated common occurrences, and be- 
come rather inflexible norms against which new experiences are evaluated. One possible innate expectation proposed by Narmour is that when an entity repeats, it will continue to repeat; thus, the innate expectation after AA is that another A will follow. It is quite possible that the same presumed environmental preponderance of such repetition patterns that promote an innate expectation could be acquired during the lifetime. This distinction is empirically testable, and might be carried out, for example, with variations in the "peek-a-boo" game played with infants (Parrott \& Gleitman, 1989).

The AAB pattern, which we will demonstrate is very common in music and humor, is tailor-made to capture the experience of violation of an innate (or strong acquired) expectation. The presence of two "A"s clearly defines A as a unit and establishes a repetitive structure that implies another A. The "B" departs from this expectation in some way, and if this way is generally consonant with the style at hand (as opposed, for example, to the sound of a fog horn), there is a constrained violation of expectation. The $\mathrm{AB}$ pattern falls short in these terms because the establishment of a repeating unit has not been accomplished. The AAAB pattern surely accomplishes the same type of violation, but less efficiently, since two A's are sufficient to establish the pattern to be violated. Further, the third A matches the initial expectations set up by the first two A's and thus runs the risk of boring the art consumer. The composer or comedian might, however, take advantage of the sophisticated audience's stylistic knowledge and give the third A, which although expected innately, is not expected stylistically. Thus, although we will argue that there is good aesthetic reasoning behind the prevalence of $\mathrm{AAB}$ as opposed to $\mathrm{AB}$ and $\mathrm{AAAB}$, the perception and cognition of art is complex and offers many possibilities for artists to play with both innate and learned expectations.

In practice, in both music and humor, the $\mathrm{AAB}$ form undergoes some characteristic modifications. These basically take two forms. In one, the "B" is actually "ab," (read: "A which becomes B") that is, the third unit starts out as if it will be another " $A$ " but changes course before the A is completed. In the second form, the repeating A's are not identical, but share a common core and establish a progression from one to the other. This is illustrated, for example, in the classic priest, minister, rabbi jokes, or in music, with melodic sequence in which the second iteration is identical to the first except that the pitch height has changed. Often, the second iteration is one scale unit higher (or lower), with the third iteration one further scale unit higher (or lower). This type of variation generates an AA'B form, or an AA'a'b form, where A' represents the modified version of A. An example of AA'a"b is presented in the opening theme from Mozart Piano sonata in A major, shown in Figure 1. The original five note motive (A) is repeated a step lower $\left(A^{\prime}\right)$, and then begins again a step yet lower (a"), but changes form to another note sequence, $b$.

An equivalent AA'a"b form is typical in jokes, as illustrated in the following joke:

(A) Some men are about to be executed. The guard brings the first man forward, and the executioner asks if he has any last requests. He says no, and the executioner shouts, "Ready! Aim!"

Suddenly the man yells, "Earthquake!"

Everyone is startled and looks around. In all the confusion, the first man escapes.

(A') The guard brings the second man forward, and the executioner asks if he has any last requests. He says no, and the executioner shouts, "Ready! Aim!"

Suddenly the man yells, "Tornado!"

Everyone is startled and looks around. In all the confusion, the second man escapes.

(a"b) By now the last man has it all figured out. The guard brings him forward, and the executioner asks if he has any last requests. He says no, and the executioner shouts, "Ready! Aim!"

And the last man yells, "Fire!"

In this particular joke, the "violation" (b) fits quite nicely into the form of the prior A's, but involves a different construal of the final word. The expectation is created of another disaster word, but when the third one is uttered, it has a very different, unexpected meaning.

The idea of a break with expectation, or a "script reversal," has been used by Norrick (1993) and others to explain this type of humor. Norrick notes that this formulation accounts for "many well-known jokes, especially those built around competition between representatives of three nationalities, three religions, and so on" (p. 391). Note the reference to the "threeness" that characterizes the AAB pattern. Hetzron (1991) presents a similar analysis, analyzing certain jokes into "pulses" which correspond to units like A. He notes that rhythmic pulses set up a pattern to be utilized in the joke: ". . .the non final pulses are here not necessary as parts of the humorous element of the joke. They are preparatory; they build up an automatism that will be exploited later. They provide

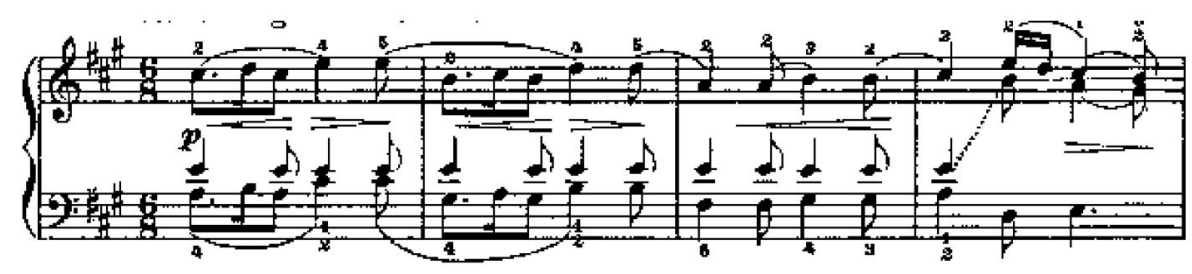

$\underline{A}$

$\underline{A^{\prime}}$

$\underline{a}$ 'b

Figure 1. Ex. 1. AAB structure in the initial theme from Mozart, Sonata in A major, K. 331, I (Andante grazioso), mm. 1-4. 
a recurring pattern, the regularity of which supplies good ground for the placing of the punchlines" (p. 73).

The issues we have presented, from both the humor and music literature, along with the idea of efficiency, the desirability of producing an aesthetic effect with a minimal amount of material, cause us to make the following two predictions:

a) the $\mathrm{AAB}$ pattern will be common in music and jokes, and more frequent than either the $\mathrm{AB}$ or $\mathrm{AAAB}$ pattern. In this prediction, the $\mathrm{AB}$ pattern is a bit problematic; since there is no repetition of $\mathrm{A}$, it can be difficult to determine when $\mathrm{A}$ ends and B follows. However, usually there are internal cues (as in the final line of each joke segment above, or a pause or some type of closure in musical presentations) that mark the events. Thus, in the joke above, if "Fire" was uttered by the second person, we would clearly have an Aab pattern.

b) the $\mathrm{AAB}$ pattern will be superior to the $\mathrm{AB}$ pattern in generating humor, and at least as good as the AAAB pattern.

We test hypothesis (a) for music and jokes in Studies 1 and 2, and hypothesis (b) for jokes in study 3 .

\section{Study 1: Incidence of the AAB Pattern in Music}

$\mathrm{AAB}$ appears in many styles of music, in all musical parameters, and at many durational levels. For the present purpose, we need to limit how and where we look for $\mathrm{AAB}$ patterns. First, we will consider only melody. $\mathrm{AAB}$ (as well as $\mathrm{AB}$ and $\mathrm{AAAB}$ ) also occurs in harmony, dynamics, timbre, and other parameters but perhaps is most obvious in melodic structure. Second, we will sample pieces of music from the Western art music tradition as well as Broadway and jazz standards found in a typical "fake book." Lastly, we restrict ourselves to melodic patterns at a durational level of one to four measures.

This last constraint is of particular importance for all types of melodic patterns can and do appear at many levels of musical structure. One could find patterns at the note-to-note level as, for example, in the opening 4-note motive from Beethoven's Symphony No. 5 in C Minor, an example of AAAB. On the other end of the spectrum, one could find such patterns at the level of musical form as in bar form. Found commonly in Wagner's operas, bar form consists of an initial section that is repeated and followed by a contrasting section (AAB). We choose the 1-4 measure motive or subphrase because such durations seem to be perceptually real. That is, unlike the case of an entire movement of a symphony, a listener can retain a short motive in short-term memory thus making the repetition much more apparent.

Another problem with sampling music to find melodic patterns is that such patterns occur many times in one piece. Rather than attempting an exhaustive analysis of each example, we choose to examine only the opening 16 bars of each piece, allowing for three iterations of a 4-bar A and a 4-bar B, the longest possible unit given our constraints.

A more pressing concern is how to define what $\mathrm{A}$ is. In some examples (as with the Mozart melody in Figure 1), no problem exists. The melodic sequence in measure two clearly defines the first measure as a unit (A) which thus defines the second measure as a unit (A'). The third measure begins as we expect (a") but ends quite differently (b) thus creating an AA'(a"b). Other examples present more obstacles. Without repetition and articulation within phrases, it is difficult to define where A ends and something else (B) begins.

\section{Method}

For a sampling of Western art music from chant to contemporary music, we examined every other piece in Charles Burkhart's Anthology for Musical Analysis, Fifth Edition (1994). For a sampling of jazz and Broadway standards, we analyzed every other example in The Ultimate Jazz Fakebook (Wong, 1988). One of the authors (AR), trained in music theory, examined each of the first 16 measures in the two musical sources, and classified them as $\mathrm{AB}, \mathrm{AAB}, \mathrm{AAAB}$ or other. In cases where there was ambiguity about classification, the default category was $A B$, which would work against our hypothesis.

\section{Results}

Table 1 summarizes the results. For Western art music, the distribution of $\mathrm{AB}, \mathrm{AAB}$, and $\mathrm{AAAB}$ departs significantly from chance $\left(\chi^{2}[2,80]=\right.$ $22.56, p<.001$ ). For jazz/popular music, the discrepancy is also significant $\left(\chi^{2}[2,107]=56.88, p<.001\right)$. AAB is more common than AAAB in both Western Art music (ratio: $\mathrm{AAB} / \mathrm{AAAB}=4.89$ ) and Jazz popular music (ratio: $\mathrm{AAB} / \mathrm{AAAB}=5.62$ ) (both significant at $p<.001$ by one-tailed binomial test). $\mathrm{AAB}$ is more common than $\mathrm{AB}$ in Western Art music (ratio: $\mathrm{AAB} / \mathrm{AAAB}=1.52, p<.05$, binomial) and jazz/popular music (ratio: $\mathrm{AAB} / \mathrm{AAAB}=3.17, p<.001$, binomial).

\section{Study 2: The Incidence of the AAB Pattern in Jokes}

\section{Method}

A large compendium of jokes (several thousand) in English was accessed on the internet (jokes2000.com). This site allowed us to search for target words. We used two techniques to estimate the number of $\mathrm{AB}, \mathrm{AAB}$, and $\mathrm{AAAB}$ jokes. One was to actually read all of the jokes $(1,157)$ added to the site in 1999 and 2000. Each joke was evaluated in terms of the categories we have set out. A single reader (blind to our hypothesis) examined each joke and classified it as $\mathrm{AB}, \mathrm{AAB}, \mathrm{AAAB}$, or other. Of course, the great majority fell in the "other."

A second procedure was less direct, but allowed us to scan a much larger number of jokes. We searched the entire Jokes2000 database for the three words: "second," "third," and "fourth." It seemed a reasonable assumption, based on a common form for jokes of this sort (e.g., the first Y did X, then the second $\mathrm{Y} \operatorname{did} \mathrm{X} . .$.$) , that these words would almost always signal this$ joke format. These data are all based on the assumption that the presence of the word "third" and the absence of the word "fourth" within a joke

Table 1

Summary of Results From Search for Melodic Patterns in Western Art Music and Jazz/Popular Music Compendiums, and Reading of 1,157 Jokes

\begin{tabular}{|c|c|c|c|c|c|c|}
\hline & \multicolumn{2}{|c|}{$\mathrm{AB}$} & \multicolumn{2}{|c|}{$\mathrm{AAB}$} & \multicolumn{2}{|c|}{$\mathrm{AAAB}$} \\
\hline & $N$ & $\%$ & $N$ & $\%$ & $N$ & $\%$ \\
\hline Western/art & 29 & 35.3 & 44 & 53.7 & 9 & 11.0 \\
\hline Jazz/popular & 23 & 21.1 & 73 & 67.0 & 13 & 11.9 \\
\hline Jokes 2000 & 31 & 20.5 & 109 & 72.2 & 11 & 7.3 \\
\hline
\end{tabular}


imply the AAB pattern (and similarly, AB if the joke included the word "second" but not "third.). To test this assumption, a small sample of twenty jokes containing the word "third" but not "fourth" was examined, and it was found that $75 \%$ of them were indeed $\mathrm{AAB}$ jokes. We adjusted our joke form counts to $75 \%$ of critical word pattern incidence to compensate for this.

\section{Results}

Of 1,157 jokes in the corpus, $217(18.8 \%)$ qualified as being in the $\mathrm{AB}$ or longer repetitive form. (In the following tabulation, we do not include any items in the peculiar joke form in which a short punchline occurs just after a full completion of an A segment.) The distribution of jokes across the three patterns $(\mathrm{AB}, \mathrm{AAB}, \mathrm{AAAB}$, see Table 1) was significantly discrepant from chance $\left(\chi^{2}[2,149]=106.54, p<.001\right)$. As show in Table 1 , there is a predominance of $\mathrm{AAB}$ frames, which occur 3.52 times more frequently than $\mathrm{AB}(p<.001$, one-tailed binomial) and 9.91 times more frequently than $\mathrm{AAAB}(p<.001$, binomial $)$.

For the estimated joke frequency, based on mention of ordinal numbers, in addition to the .75 adjustment for each frequency (mentioned in the method section, to compensate for the fact that some ordinal word mentions are not part of an ordinal sequence), we had to make another adjustment. Unlike "first," "third," and "fourth," the word "second" has a nonordinal meaning, as a unit of time. We sampled 36 hits for the word "second," and found that $75 \%$ of them used the word in an ordinal manner. We therefore corrected the prior "second" total, reducing it to $75 \%$ of the original level. With this corrected value, we find (Table 2), as predicted, that there is a very modest drop off between frequency of "second" and "third," but a very sharp drop off between "third" and "fourth," supporting the position that AAB is much more common than AAAB (Table 2).

There are two problems with the analysis as we have developed it so far. One is that there may be a common form for AB jokes that uses "next" instead of "second." Of course, the "next" form could also be used in an $\mathrm{AAB}$ joke, but it is possible that we are underestimating the number of $\mathrm{AB}$ jokes to a modest extent. In the jokes2000.com database, we searched for the word "next" and obtained 287 hits. We examined the first 30 of these and found that in 23 cases the word "next" was not used in an AB type joke. Of the remaining seven cases, six were in $\mathrm{AAB}$ format, and one was in AAAAB format. Hence, if anything, the "next" problem is more likely to reduce our predicted effect size than to increase it. The other problem is that we must find a "control" listing of these words, so that we can produce a baseline of frequency of "second," "third," and "fourth" in nonjoke English. Once again, we face the problem of the dual meanings of "second," and so we must adjust the "second" number by sampling uses of "second" and determining what percent refer to an ordinal number. We made such a search and compensation on a web-based edition of the Washington Post (February 1, 2001) and another on the New York Times web site; these values, corrected for nonordinal uses of "second" from the same text, appear in Table 2. With respect to the incidence of "second," there is a modest drop in the incidence of "third" but a very sharp drop in the incidence of "fourth," for jokes. No such discontinuity appears in either of the newspaper databases; rather, the gradual drop from second to third to fourth seems more or less linear.

In order to render the figures generated from these three databases more comparable to the other music and joke data, we inferred the frequency of each of the three critical patterns $(A B$ $\mathrm{AAB}$, and $\mathrm{AAAB}$ [or more than $3 \mathrm{As}$ ]) from the frequency data. For example, there were 170 mentions of "second" (compensated) in the joke database, and 127 mentions of "third." We infer that there were $43 \mathrm{AB}$ pattern jokes (170-127). We made the same calculations to arrive at the frequencies of $\mathrm{AAB}$ (mentions of "third" minus "fourth"), and AAAB or more (number of "fourths"), and did so for the joke, New York Times and Washington Post databases. These numbers are presented in the last three rows of Table 2. Note the preponderance of AAB forms in the jokes, whereas the $\mathrm{AAAB}$ (or more) form was most common in both Newspaper data bases.

We tested for the significance of these different patterns with two $X^{2}$ statistics, pitting jokes separately against the Washington Post and the New York Times (as arrayed in the last three rows of

Table 2

Compensated Frequency of Words "Second," "Third," and "Fourth" in Jokes and Other Texts, and Inferred Frequency of Three Critical Joke Pattern

\begin{tabular}{lccc}
\hline & Jokes2000.com & $\begin{array}{c}\text { New York } \\
\text { Times }\end{array}$ & $\begin{array}{c}\text { Washington Post } \\
\text { (Feb. 1, 2001) }\end{array}$ \\
\hline $\begin{array}{l}\text { Instances of "second" (readjusted) } \\
\text { Instances of "third" }\end{array} \quad 170$ & 716 & 85 \\
$\quad$ (percent of above cell) & 127 & 567 & 55 \\
Instances of "fourth" & $(75 \%)$ & $(79 \%)$ & $(65 \%)$ \\
$\quad$ percent of above cell) & 22 & 344 & 33 \\
Inferred frequency of AB" & $(17 \%)$ & $(48 \%)$ & $(39 \%)$ \\
Inferred frequency of AAB & 43 & 149 & 30 \\
Inferred frequency of AAAB or more & 105 & 223 & 22 \\
\hline
\end{tabular}

Note. All raw number counts in jokes are reduced by $25 \%$ to compensate for uses of the ordinal number words in situations other than repetitive jokes. In addition, the number of uses of "second" in all sources is reduced by an additional $25 \%$ to compensate for estimated uses of the word "second" as a unit of time, rather than as an ordinal number.

"Mentions of "third" (second row above) minus "second" (first row above). " Mentions of "fourth" (third row above) minus "third" (second row above). "Mentions of "fourth" (third row above). 
Table 2). For the joke-NY Times comparison, $\chi^{2}(2,846)=74.242$ $(p<.001)$; the comparable value for joke-Washington Post is, $\chi^{2}(2,257)=34.229(p<.001)$. Given these very significant differences, we now examine the data on joke pattern in more detail. The distribution of the three forms is far from random, $\chi^{2}(2,168)=65.73(p<.001)$. Specifically, the AAB ("third" without "fourth"), at 105, is significantly higher than $A B$, at 43 and $\mathrm{AAAB}$, at 22 (both significant at $p<.001$ by two-tailed binomial).

\section{Study 3: The Degree of Humor in $\mathrm{AB}, \mathrm{AAB}$, and $\mathrm{AAAB}$ Jokes}

In this experiment, we directly test whether the more common $\mathrm{AAB}$ form in jokes is also generally the funniest. We do so by adding or subtracting $\mathrm{A}$ segments from existing jokes, and thus generating sets of $\mathrm{AB}, \mathrm{AAB}$, and $\mathrm{AAAB}$ forms for each joke. Each member of a set has the same last punchline (B). Participants rate the funniness of the jokes, in a between participant design, such that each participant hears only one of the three forms of each joke.

\section{Method}

Participants. Participants were 165 subjects from an introductory psychology course at the University of Pennsylvania, who received extra course credit for their participation, and 69 volunteers from the Philadelphia Jury Pool (itself, a random selection of Philadelphia citizens). The jury pool members received a candy bar for their participation.

Procedure. The participants in this study were given a handout/packet containing all of the stimuli for this experiment. It began with instructions that read:

"Thank you for participating in our study on jokes. We are just trying to see how funny people think different jokes are. You will read nine jokes. After each joke you will rate how funny you think it is. Then, at the end, you will give us some information about yourself (such as your age and religion). This questionnaire is anonymous: we do not ask for your name."

After each printed joke, there was a 10 point rating scale, anchored at $0=$ not funny at all and $10=$ extremely funny.

Stimuli. Each participant received one of three versions of a set of nine jokes. All contained the same sequence of nine jokes, but six were modified in terms of number of A segments across the different versions. Three "filler" jokes, in positions 2,5 , and 8 were the same for all participants and served two purposes. First, they provided a "cover" for the experimental manipulations because none of the three had anything like an AAB format. Second, they allowed for a way to calibrate each individual in terms of manner of use of the humor scale.

In addition to the three identical items, each of the three versions of the questionnaire contained two jokes in the $\mathrm{AB}$ form, two in the $\mathrm{AAB}$ form, and two in the $\mathrm{AAAB}$ form. Each of the six varied jokes was created in the three forms (AB, AAB, AAAB). For instance, Joke 1 was in the $\mathrm{AB}$ form on handout one $(n=76), \mathrm{AAB}$ form on handout two $(n=81)$, and $\mathrm{AAAB}$ form on handout three $(n=77)$.

Of the original jokes, two were in each of the three forms $(\mathrm{AB}, \mathrm{AAB}$, $A A A B)$. For jokes in the original $A_{3} A_{2} A_{1} B$ forms, the two alternatives were created by striking $A_{3}$ (making $A_{2} A_{1} B$ ) or striking $A_{3}$ and $A_{2}$ (making $A_{1} B$ ). For jokes originally in the $A B$ form, two additional As (that is, $A_{3}$ and $A_{2}$ ) were created, and grafted on before the original $A$, to make $A_{2} A_{1} B$ and $A_{3} A_{2} A_{1} B$ forms. Appropriate additions and deletions were made for jokes in the original $\mathrm{AAB}$ form. For example, we present the AAAB form of Joke 3 used in this study. This joke was $A B$ in its original form.
The phrase added to make this an AAB joke is indicated in italics in its proper place in the sequence. The phrase added to the $\mathrm{AAB}$ to make an $\mathrm{AAAB}$ joke is added below in italics:

Some friends were having a drink in a London pub at lunchtime. After conversing for a while, one said, "I had a terribly embarrassing experience last evening. I went up to the ticket window, meaning to purchase a ticket to Piccadilly, and instead I asked for a ticket to Tickadilly!”

$(A A B)$ "I know just what you mean," replied one of the chaps. "I went to the post office, meaning to ask for a first class stamp, and instead I asked for a first class tramp."

$(A A A B)$ One of the other men replied, "I had a similar experience. I went to the airport meaning to buy a ticket to Baltimore, but instead asked for a ticket to Faltimore."

(B) The next chap replied, "I had a similar experience. Only this morning at breakfast I meant to ask my wife to please pass the butter. Instead, to my acute embarrassment, I said, 'You hopeless bitch, you ruined my life."”

The sequence of jokes was exactly the same in all three versions, and the order of the different numbers of repetitions is provided in Table 3.

\section{Results}

Ratings for the six critical jokes in which the AAB format was varied (jokes 1, 3, 4, 6, 7, 9) by each participant are partly a function of the general "humor sensitivity" of the participant, as well as the way that participant happens to use the rating scale. In order to compensate for these aspects of the ratings, which were irrelevant and noise-producing with respect to the hypothesis in question, we equalized participants in terms of their scores on the three filler jokes common to all participants. We calculated a mean score for the three filler jokes $(2,5,8)$ for each participant, and then calculated the mean of these scores across all participants. We then adjusted the ratings for each participant on the six critical jokes, by adding to each score for each participant the difference between their mean on the three filler jokes and the mean of the entire sample. Thus, if a particular participant rated the three filler jokes as 3.90, in comparison to the actual full sample mean of 3.35, we would subtract .55 from all of the critical joke scores of that participant.

Table 3 displays the mean ratings for each group on the compensated ratings for each of the critical jokes.

Table 3

Mean Compensated Ratings for Each of the Critical Jokes

\begin{tabular}{|c|c|c|c|c|c|c|}
\hline Joke & $\mathrm{AB}$ & $\mathrm{AAB}$ & AAAB & $\begin{array}{l}\text { Best } \\
\text { form }\end{array}$ & $\begin{array}{l}\text { Worst } \\
\text { form }\end{array}$ & $\begin{array}{c}F \\
\text { value } \#\end{array}$ \\
\hline 1 & 4.43 & 4.74 & 4.25 & $\mathrm{AAB}$ & $\mathrm{AB}$ & .412 \\
\hline 3 & 3.54 & 3.86 & 3.70 & AAB & $\mathrm{AB}$ & .333 \\
\hline 4 & 4.30 & 5.20 & 4.84 & $\mathrm{AAB}$ & $\mathrm{AB}$ & 2.137 \\
\hline 6 & 4.46 & 4.35 & 4.62 & AAAB & $\mathrm{AAB}$ & .170 \\
\hline 7 & 4.43 & 5.36 & 5.49 & AAAB & $\mathrm{AB}$ & $3.949 *$ \\
\hline 9 & 4.99 & 5.29 & 4.96 & $\mathrm{AAB}$ & $\mathrm{AAAB}$ & .383 \\
\hline Overall mean & 4.35 & 4.80 & 4.65 & AAB & $\mathrm{AB}$ & \\
\hline
\end{tabular}

$* p<.05$, by Scheffe test, $\mathrm{AB}$ vs AAAB $p=.039, \mathrm{AB}$ vs $\mathrm{AAB} p=.081$ \#df $(2,231)$. 
The predominant, but not exclusive pattern of the results, is for $\mathrm{AAB}$ to be the best joke (4/6 cases) and $\mathrm{AB}$ to be the worst joke $(4 / 6)$ cases, both as predicted. The binomial probability that $A B$ would never be the best joke over 6 jokes is $(2 / 3)$ to the sixth power, or .087. In only one of the jokes (\#7) are the differences among the three forms significant by one way ANOVA (Table 3), and in this case, $\mathrm{AB}$ is lowest, and only significantly different (by Scheffe tests) from the AAAB form, although the AAB and AAAB forms are very close in value (Table 3 ).

The most comprehensive test of our hypothesis combines the results from the two exemplars of each form for each participant. Thus, each participant generates three humor scores, the average each of the two $\mathrm{AB}, \mathrm{AAB}$, and $\mathrm{AAAB}$, all corrected for baseline of humor ratings. A repeated measures one way ANOVA of the set of three scores from each participant was significant, $F(2,232)=$ $3.787, p=.028$. The AAB form is significantly funnier than the $\mathrm{AB}$ forms (mean difference $=.45, t(233)=2.724, p=.007$, or $p=.02$ with the Bonferroni compensation for the three t-tests). This, the critical prediction of the AAB hypothesis, is the only significant difference. The AAAB-AAB difference (.15), though in the predicted direction, is not significant, nor is the AAAB-AB difference (.30).

\section{Discussion}

We have established the predominance of the AAB form in two genres: music across four centuries and a large sample of contemporary jokes. We have also provided modest evidence, experimentally, that for one set of jokes, the AAB form is the funniest form. These findings all support the AAB hypothesis.

Assuming that future results support both the predominance of the AAB pattern and its greater aesthetic success, there would be strong support for the implication-realization type of formulation. This type of study (frequency in the aesthetic domain and aesthetic success) does not speak directly to Narmour's interesting claim about innate expectations of repetition. The results are consistent with this view, but just as consistent with the idea that there is a repetition norm, perhaps acquired by direct experience with the world, perhaps acquired in the more limited frames of particular aesthetic media. Different types of studies, organized in familiar nature-nurture empirical frames, would have to be done to enlighten this issue.

We note that the $\mathrm{AAB}$ predominance in artistic productions that we have sampled (music and jokes) is substantial, but that the $\mathrm{AAB}$ increased aesthetic effect on the audience is small, based on our one experiment. One should not generalize too much from a single experiment, but it is quite possible that the aesthetic advantages of $\mathrm{AAB}$ on an audience are small. Nonetheless, with the extraordinary number of iterations of many aesthetic works, a small difference might amount to something of importance in the real world. This would also argue for implicit or explicit high sensitivity on the part of authors/composers to subtle differences in aesthetic effect.

The purported audience advantages of $\mathrm{AAB}$ over $\mathrm{AB}$ come at the cost of decreased efficiency; that is, more time/space is required to present $\mathrm{AAB}$ than $\mathrm{AB}$. On the other hand, we see no clear ground to confidently predict that $\mathrm{AAAB}$ will have a greater aesthetic appeal than AAB. The violation of expectation argument seems to use up most of its force after AA. Rather, our account of why $\mathrm{AAB}$ is more common than $\mathrm{AAAB}$ has to do with efficiency. That is, it is focused more on the author/composer than the audience. Of course, with major differences in efficiency, the aesthetic experience would be responsive to efficiency differences. One laugh an hour is not as pleasing as one laugh a minute. However, the $\mathrm{AAB}$ vs. $\mathrm{AAAB}$ differences in length/time might be so small as not to "count" in the aesthetic experience. If these speculations have any merit, we would predict that the larger the $\mathrm{A}$ unit (in any medium), the stronger the predominance of $\mathrm{AAB}$ over AAAB.

We consider our hypothesis and results a beginning in the understanding of temporal patterns that generate aesthetic experiences. $\mathrm{AAB}$ is only one of many possible sequences, and repetition is frequent but not ubiquitous in aesthetic productions. With respect to $\mathrm{AAB}$, our findings confirm our hypothesis, but of course, further study is needed to buttress our conclusion. In our view, this paper highlights a little-noticed phenomenon that exists across at least two aesthetic domains. We have provided a theoretical account for it and present modest evidence for our contention that the $\mathrm{AAB}$ form is most successful with the audience. Our experiment (study 3), is, we believe, well designed and in some sense paradigmatic for studies that would further explore this and related areas. But the conclusions from this study are weak, though supportive of our claims. It is a first experimental study, a beginning. If, as the study suggests, form differences generate only modest differences in aesthetic response, future studies will have to be well balanced and include a fairly large number of subjects to detect effects. Surely, a study parallel to our joke study could be done for short musical selections. As well, we believe a similar $\mathrm{AAB}$ pattern exists in poetry and perhaps in some ways in the visual arts. Future work would have to assess these possibilities, as well as test for the aesthetic response to different forms in the new media.

\section{References}

Berlyne, D. E. (1971). Aesthetics and psychobiology. New York: AppletonCentury-Crofts.

Burkart, C. (ed.) (1994). Anthology for musical analysis, fifth edition. Fort Worth, Texas: Harcourt College Publishers.

Ellsworth, P. C., \& Scherer, K. R. (2003). Appraisal processes in emotion (Chapter 29). In R. J. Davidson, K. R. Scherer, H. H. Goldsmith (eds.), Handbook of affective science (pp. 572-595). Oxford, UK: Oxford University Press.

Frijda, N. H. (1986). The emotions. Cambridge, UK: Cambridge University Press

Gaver, W. W., \& Mandler, G. (1987). Play it again, Sam: On liking music. Cognition and Emotion, 1, 259-282.

Hetzron, R. (1991). On the structure of punchlines. International Journal of Humor Research, 4, 61-108.

Kubovy, M. E. (1999). On the pleasures of the mind. In D. Kahneman, E. Diener \& N. Schwarz (eds.), Well being: The foundations of hedonic psychology. (pp. 134-154). New York: Russell Sage.

Meyer, L. B. (1956). Emotion and meaning in music. Chicago: University of Chicago Press.

Meyer, L. B. (1973). Explaining music: Essays and explorations. Chicago: University of Chicago Press.

Narmour, E. (1990). The analysis and cognition of basic melodic structures. Chicago: University of Chicago Press.

Narmour, E. (1991). The top-down and bottom-up systems of musical 
implication: Building on Meyer's theory of emotional syntax. Music Perception, 9, 1-26.

Narmour, E. (1992). The analysis and cognition of melodic complexity. Chicago: University of Chicago Press.

Norrick, N. R. (1993). Repetition in canned jokes and spontaneous conversational joking. International Journal of Humor Research, 6, 385402 .

Oatley, K. (2003). Creative expression and communication of emotions in the visual and narrative arts. In R. J. Davidson, K. R. Scherer, \& H. H. Goldsmith (eds.), Handbook of affective science (pp. 481-502). Oxford, UK: Oxford University Press.

Parrott, W. G., \& Gleitman, H. (1989). Infants' expectations in play: The joy of peek-a-boo. Cognition \& Emotion, 3, 291-311.
Rozin, P. (1999). Preadaptation and the puzzles and properties of pleasure. In D. Kahneman, E. Diener, \& N. Schwarz (eds.), Well being: The foundations of hedonic psychology. (pp. 109-133). New York: Russell Sage.

Scherer, K. R. (1984). On the nature and function of emotion: A component process approach. In K. R. Scherer and P. Ekman (eds.), Approaches to emotion (pp. 293-318). Hillsdale, N. J.: Erlbaum.

Wong, H. (ed.) (1988). The ultimate jazz fakebook. Milwaukee, Wisconsin: Hal Leonard Corporation.

Received May 2, 2005

Revision received January 3, 2006

Accepted January 26, 2006

\section{E-Mail Notification of Your Latest Issue Online!}

Would you like to know when the next issue of your favorite APA journal will be available online? This service is now available to you. Sign up at http://watson.apa.org/ notify/ and you will be notified by e-mail when issues of interest to you become available! 